\section{A New Glycoside from Madder}

Alizarin and purpurin have always been described as the two chief tinctorial substances of madder. I have found that the purpurin obtained from madder does not derive from a previously suspected purpurin glycoside but from a glycoside of pseudopurpurin. (Alizarin is $1: 2$-dihydroxyanthraquinone, purpurin is $1: 2: 4$-trihydroxyanthraquinone and pseudopurpurin is purpurin 3-carboxylic acid.)

While ruberythric acid (the alizarin glycoside) has been known for many years, the second tinctorially important glycoside of madder has not been previously isolated; though its presence was first recognised by Kopp in 1861. A glycoside of pseudopurpurin has now been prepared by me from the roots of the wild madder (Rubia peregrina) and the yellow bedstraw (Galium verum). The substance is very soluble in water, from which it readily crystallises in minute needles, and forms a bright yellow powder, showing no definite melting point owing to decomposition. It appears to be a l-monopentoside of pseudopurpurin, and is very easily hydrolised. It can be isolated as follows. Fresh roots being extracted with boiling water, normal lead acetate precipitates the crude glycoside. The presipitate is extracted with 1 per cent acetic acid, impurities removed by the addition of more lead acetate, and then ammonia throws down a purer lead compound which is decomposed by 1 per cent $\mathrm{H}_{2} \mathrm{SO}_{4}$. The glycoside is extracted from the acid solution with butyl alcohol, and then removed by aqueous ammonium carbonate. The ammonia being blown off by air on a water bath, the warm concentrated aqueous solution gives crystals of the glycoside on cooling.

As the glycoside of pseudopurpurin is found only in the genera of the tribe Galiece of the Rubiacece, the name 'galieide' is suggested for this substance.

Galieide is responsible for the dyeing properties, known in antiquity, of our native bedstraws (Galium). Alizarin occurs only in small quantities in a few species, but the dyers' madder (Rubia tinctorum), which is scarcely found apart from cultivation, yields equal quantities of alizarin and pseudopurpurin. Alizarin was the most useful constituent from the dyers' point of view as it was the only one involved in the dyeing of turkey red with madder. The wild madder ( $R$. peregrina) has strong tinctorial properties due mainly to galieide, and contains only a negligible amount of alizarin.

\section{Biochemical Laboratory,}

R. HாL. Cambridge.

\section{Microchemical Detection of Elementary Sulphur}

THE only method so far known for the detection of small amounts of elementary sulphur is unsatisfactory : it consists, in principle, in isolation of the free sulphur of the material under test by sublimation or extraction, followed by examination of the crystal form and of the chemical reactions. Fractions of a milligram of elementary sulphur cannot be detected by this method, and it also fails with larger amounts if the sample contains organic substances which, like sulphur, sublime and have similar solubility.

The following method, which is free from the above disadvantages, has been worked out, chiefly for the purpose of detecting free sulphur, in the presence or absence of combined sulphur, in biological material. The substance to be tested is thoroughly ground with benzylimido-di-( $p$-methoxyphenyl)methane (I) and a sample of the mixture is introduced into a melting point tube. The tube is placed for five minutes in a bath previously heated to $210^{\circ}$ and then the contents of the tube are extracted with a few drops of benzene. If the substance contains elementary sulphur the extract is coloured blue. This blue colour decreases in intensity within a few hours if a crystal of mercuric chloride is added, and the surface of the crystal acquires an intense red colour. The blue colour appears as the result of the formation of the blue thioketone, $p p$-dianisylthioketone (II), whilst the red colour is due to the formation of an addition compound of the thioketone and mercuric chloride. The addition compound has the constitution (III) or (IV).

Very small amounts $(0.04 \mathrm{mgm}$.) of elementary sulphur can be detected without difficulty by this method. The reagent $(\mathrm{I})$ does not react with combined sulphur.

$$
\begin{array}{rlr}
\mathrm{Ar} & =p-\mathrm{CH}_{3} \cdot \mathrm{O} \cdot \mathrm{C}_{6} \mathrm{H}_{4}- & \\
\text { (I) } \mathrm{Ar}_{2}: \mathrm{C}: \mathrm{N} \cdot \mathrm{CH}_{2} \mathrm{C}_{6} \mathrm{H}_{5} \stackrel{\mathrm{s}}{\longrightarrow} & \mathrm{Ar}_{2}: \mathrm{C}: \mathrm{S} \text { (II) } \\
\text { (III) } \mathrm{Ar}_{2}: \mathrm{C}: \mathrm{S} \ldots \ldots \mathrm{Hg} \mathrm{Cl} \mathrm{Hg}_{2} & {\left[\mathrm{Ar}_{2}: \mathrm{C}\right] \mathrm{Cl} \text { (IV) }} \\
& \dot{\mathrm{S}} \mathrm{HgCl}
\end{array}
$$

The reagent (I) is obtained by the action of benzylamine on the chloride of dianisylketone $\left(\mathrm{Ar}_{2}: \mathrm{C}: \mathrm{Cl}_{2}\right)$, or by the action of dianisylthioketone (II) on benzyl azide $\left(\mathrm{C}_{6} \mathrm{H}_{5} \cdot \mathrm{CH}_{2} \cdot \mathrm{N}_{3}\right)$.

My thanks are due to W. Urban for his co-operation in this work.

Alexander Schönberg.

Technische Hochschule,

Berlin-Charlottenburg.

Medical Chemistry Dept.,

University of Edinburgh.

\section{The $p \mathrm{H}$ of Serum Inactivated by Heat}

WE have shown, in recent years, that the inactivation of serum, or destruction of alexin by heat, is accompanied by a number of physical or physicochemical phenomena which characterise the critical temperature of $55^{\circ}-57^{\circ} \mathrm{C}$. They are : increase in viscosity (after an absolute minimum around $56^{\circ} \mathbf{1}$ ), increase in rotatory power ${ }^{2}$, increase in absorbed light $^{3}$, increase in scattered light ${ }^{3}$, increase in the factor of depolarisation ${ }^{4}$, increase in electric resistivity $^{5}$, sharp change in the rate of sedimentation of globulins after dilution with water ${ }^{6}$, decrease in the amount of ether fixed by shaking? ${ }^{7}$ change in the interfacial tension against oils ${ }^{8}$. A new phenomenon is to be added to the list, namely, an increase in the hydrogen ion concentration, expressed by a drop in the $p \mathrm{H}$.

Up to the present time, the data provided by literature were scant and contradictory. Lieberman, Tangl (1907), Seligman (1908), Hugo Hecht (1923), for example, state that inactivation of serum is accompanied by an alkalinisation, while Michaelis and Rona (1909) and Davidsohn (1910) found that no change greater than the experimental errors took place. Sörensen and Jürgensen (1911-13), who worked on the $p \mathrm{H}$ of serum, did not work under the same conditions and studied mainly coagulation after acidification at $p \mathrm{H} 4 \cdot 70$. 